\title{
Frequency of Early Morbidities in Low Birth Weight Neonates at The Aga Khan University Hospital, Karachi
}

Saroop Chand ${ }^{1}$, Fayaz Ahmed ${ }^{1}$, Muhammad Hussain Shah 1, 2 , Abdul Lateef Leghari ${ }^{3}$, Parveen Usman ${ }^{1}$, Rohan Advani ${ }^{4}$, Muhammad Sohail Salat ${ }^{1}$, Shabina Ariff ${ }^{1}$

1. Pediatrics and Child Health, Aga Khan University Hospital, Karachi, PAK 2. Pediatrics and Child Health, Aga Khan Maternal and Child Care Centre, Karachi, PAK 3. Pediatrics, Aga Khan University Hospital, Karachi, PAK 4. Pediatrics, Aga Khan University, Karachi, PAK

Corresponding author: Saroop Chand, saroop_c@yahoo.com

\section{Abstract \\ Background}

Globally, approximately $14.6 \%$ children are born with low birth weight (LBW) annually. In Pakistan, this figure however reaches approximately $16 \%$. Low birth weight infants are vulnerable to develop early morbidities like hypothermia, hypoglycemia, respiratory distress syndrome and hypocalcemia. There is a scarcity of statistics which creates a gap in development of strategies for improving quality of care in developing countries. The aim of our study was to determine the frequency of early morbidities such as respiratory distress syndrome (RDS), hypoglycemia, hypothermia and hypocalcemia in low birth weight neonates.

\section{Methodology}

A prospective descriptive study was conducted via non-probability sampling technique from $1^{\text {st }}$ April 2016 to $30^{\text {th }}$ September 2016 at The Aga Khan University Hospital, Karachi. All low birth weight infants, i.e., those with birth weight < 2500 grams were included in this study and observed for early morbidities, including hypothermia, hypoglycemia, hypocalcemia and respiratory distress syndrome. Descriptive analysis was done using SPSS version 22 (IBM Corp., Armonk, NY), mean and standard deviation were determined for quantitative variables, whereas frequency and percentages were calculated for qualitative variables.

\section{Results}

A total of 2082 neonates were born during the study period, of which 271 (13\%) were born with low birth weight. One hundred and eighty-five (68.1\%) of these LBW neonates were preterm babies while 86 (31.9\%) were born at term. Among LBW neonates 137 (51.0\%) were males and 134 (49.0\%) females. In the study population, hypoglycemia was seen in $17.3 \%$, hypocalcemia in $13.6 \%$, respiratory distress syndrome in $11 \%$, and hypothermia in $2.5 \%$.

Received 10/23/2019

Review began 10/27/2019

Review ended 10/30/2019

Published 11/03/2019

\section{(c) Copyright 2019}

Chand et al. This is an open access article distributed under the terms of the Creative Commons Attribution License CC-BY 3.0., which permits unrestricted use, distribution, and reproduction in any medium, provided the original author and source are credited.

\section{Conclusion}

Our study highlighted major early morbidities of LBW neonates, and their association with birth weight, gestational age and gender. Significant association of birth weight was found with hypothermia and hypocalcemia, whereas hypocalcemia and RDS were significantly associated with gestational age. However, none of the early morbidities had significant association with gender. Keeping in perspective the early morbidities in this population we propose that priority be given to providing adequate attention to low birth weight neonates.
Categories: Obstetrics/Gynecology, Pediatrics, Public Health

Keywords: low birth weight, prematurity, early morbidities, neonates, respiratory distress syndrome, hypoglycemia, hypothermia, hypocalcemia, nicu

\section{Introduction}

Newborns with birth weight less than 2500 grams are called low birth weight (LBW) [1]. Neonatal mortality and morbidity are an alarming public health issue in most developing countries. The neonatal period ranks the highest risks of death among any period in the human lifetime [2]. In developed world, neonatal health reforms have gained focus in child health for the reduction of both morbidity and mortality. In developing countries however, strategies for improving neonatal health standards have not received significant attention.

The United Nations Children's Fund (UNICEF) estimates show that globally approximately 20 million 
children are born with LBW annually. LBW neonates prevalence is much higher in the developing countries (16.5\%) compared to developed countries (7\%); with the highest incidence in south central Asia (27\%) followed by Africa (13\%-15\%) [1,3]. Burden of LBW among neonates in Pakistan is approximately $16 \%$. LBW is predominantly due to prematurity and/or intra-uterine growth restriction (IUGR) [4], however in developing countries it is most commonly due to IUGR rather than prematurity [3-5]. Prematurity and IUGR are associated with increased neonatal morbidity and mortality [6].

Low birth weight IUGR newborns are prone to develop early morbidities such as birth asphyxia, hypothermia, hypoglycemia, hypocalcemia and polycythemia $[7,8]$, whereas preterm low birth weight neonates suffer from hypothermia, respiratory distress syndrome, apnea, hypoglycemia, seizures, jaundice, feeding difficulties, periventricular leukomalacia $[9,10]$.

Low birth weight neonates often develop hypoglycemia, evident by study conducted on neonatal hypoglycemia in babies identified as high risk, which reported a $27 \%$ incidence of hypoglycemia in low birth weight neonates [11]. In a study conducted in Shimla hospital, India regarding neonatal morbidity, $6.3 \%$ developed varying degrees of birth asphyxia, 3.9\% developed respiratory distress syndrome, $2.9 \%$ developed hypothermia [12]. In a study conducted on hypocalcemia in low birth weight neonates, early neonatal hypocalcemia was observed in approximately $24 \%$ neonates [13]. The purpose of this study was to determine the frequency of early morbidities in LBW neonates regardless of gestational age such as hypothermia, hypoglycemia, respiratory distress syndrome (RDS) and hypocalcemia.

Limited literature is available from developing countries in this regard, which hinders development and implementation of new strategies for improving quality of care in developing countries. Any step towards establishing such strategies is dependent on availability of data on early morbidities in low birth weight neonates, which can help in determining the neonatal health status at national level.

\section{Materials And Methods}

This prospective descriptive study was conducted at Neonatal Intensive Care Unit (NICU) and Well Baby Nursery of The Aga Khan University Hospital, Karachi from 1st April 2016 to 30th September 2016, after approval from the hospital ethical review committee. Our NICU is a Level III NICU with state-of-the-art facilities and a capacity of 24 beds. Neonates after appropriate management in NICU are shifted to mother baby step down unit. A total of 271 neonates born with low birth weight (<2500 grams) were enrolled by nonprobability consecutive sampling technique, out of 2082 neonates born at our institute during the study period. Inclusion criterion was neonates with birth weight $<2500$ grams regardless of gestational age. Exclusion criteria were neonate with any congenital anomalies, discharged before 72 hours of life, those who underwent any surgical procedure. All neonates who fulfilled these criteria were selected for the study after taking informed consent from their parents. Data was collected on a structured proforma which included demographics as well as variables under study including hypothermia, hypoglycemia, RDS and hypocalcemia, for which all neonates were monitored closely. Neonates were monitored during the initial 72 hours for early morbidities. Descriptive analysis was carried out using SPSS version 22 (IBM Corp., Armonk, $\mathrm{NY}$ ). Mean and standard deviations were calculated for birth weight. Frequency and percentage were calculated for early morbidities such as hypoglycemia, hypothermia, respiratory distress, and hypocalcemia. Chi-square test was conducted to understand the impact of these on result variables. $p$ value $\leqslant 0.05$ was taken as significant.

\section{Results}

During the study period, a total of 2082 neonates were born out of which 271 newborn babies fulfilled the criteria. Male to female ratio among these neonates was almost equal with 137 (51\%) being males while the rest 134 (49\%) were females. Among these neonates 185 (68.26\%) were preterm while 86 (31.7\%) were term. The mean birth weight of enrolled neonates was 2.055 kilograms $\pm 0.229 \mathrm{SD}$ and mean gestational age was 35.2 weeks $\pm 1.99 \mathrm{SD}$. The frequency of the morbidities under study was as follows: morbidities were present in $44.6 \%(n=121)$ low birth weight neonates, RDS in $11 \%(n=30)$, hypoglycemia in $17.3 \%(n=47)$, hypocalcemia in $13.6 \%(n=37)$, hypothermia in $2.5 \%(n=7)$, while $56.4 \%(n=150)$ LBW neonates had no early morbidities (Table 1). Risk estimation of the morbidity was done with gestational age, gender and birth weight by using Chi square test (confidence interval 95\%) and it was found that there was no gender predominance as far as the early morbidities were concerned ( $\mathrm{p}$-value $>0.05$ ) but significant association with gestational age ( $p$-value $<0.05$ ) was present. Similarly, the morbidities significantly declined with the increase in birth weight among the low birth weight neonates. 


\section{Cureus}

\begin{tabular}{|c|c|c|}
\hline Variable & Frequency & Percentage \\
\hline \multicolumn{3}{|l|}{ Gender } \\
\hline Male & 137 & $51 \%$ \\
\hline Female & 134 & $49 \%$ \\
\hline \multicolumn{3}{|l|}{ Gestation } \\
\hline Preterm & 185 & $69 \%$ \\
\hline Term & 86 & $31 \%$ \\
\hline \multicolumn{3}{|l|}{ Birth weight } \\
\hline$<1500$ grams & 121 & $44.60 \%$ \\
\hline $1500-<2500$ grams & 150 & $55.40 \%$ \\
\hline \multicolumn{3}{|l|}{ Early morbidities } \\
\hline Hypoglycemia & 47 & $17.3 \%$ \\
\hline RDS & 30 & $11 \%$ \\
\hline Hypocalcemia & 37 & $13.6 \%$ \\
\hline Hypothermia & 7 & $2.5 \%$ \\
\hline No early morbidity & 150 & $56.4 \%$ \\
\hline
\end{tabular}

\section{TABLE 1: Demographics and Frequency of Early Morbidities in Low Birth Weight Neonates.}

RDS: Respiratory distress syndrome

According to Table 2, hypoglycemia was present in 21 (15.3\%) of the males and 26 (19.4\%) of the females. In regard to gestational age hypoglycemia was present in nine (19.6\%) of neonates born at $<34$ weeks and in 38 $(16.9 \%)$ of neonates born at $\geqslant 34$ weeks gestation. Trends in birth weight also show a rise in occurrence of hypoglycemia with decreasing birth weight.

\begin{tabular}{|c|c|c|c|c|c|c|}
\hline & \multicolumn{4}{|c|}{ Hypoglycemia } & \multirow{3}{*}{ Total } & \multirow{3}{*}{ P Value } \\
\hline & \multicolumn{2}{|l|}{ Yes } & \multicolumn{2}{|l|}{ No } & & \\
\hline & Frequency & Percentage & Frequency & Percentage & & \\
\hline \multicolumn{7}{|l|}{ Gender } \\
\hline Male & 21 & $15.3 \%$ & 116 & $84.7 \%$ & 137 & \multirow{2}{*}{0.186} \\
\hline Female & 26 & $19.4 \%$ & 108 & $80.6 \%$ & 134 & \\
\hline \multicolumn{7}{|c|}{ Gestational age (Weeks) } \\
\hline$<34$ & 9 & $19.6 \%$ & 37 & $80.4 \%$ & 46 & \multirow{2}{*}{0.061} \\
\hline$\geq 34$ & 38 & $16.9 \%$ & 187 & $83.1 \%$ & 225 & \\
\hline \multicolumn{7}{|c|}{ Birth weight (kgs) } \\
\hline$<1.5$ & 35 & $29.7 \%$ & 83 & $70.3 \%$ & 118 & \multirow{2}{*}{0.058} \\
\hline $1.5-<2.5$ & 12 & $7.8 \%$ & 141 & $92.2 \%$ & 153 & \\
\hline
\end{tabular}

TABLE 2: Association of Hypoglycemia with Gender, Gestational Age and Birth Weight. 


\section{Cureus}

According to Table 3, respiratory distress syndrome was present in 19 (13.9\%) of the males and 11 (8.2\%) of the females. In regard to gestational age RDS was present in 15 (32.6\%) of neonates born at $<34$ weeks and in $15(6.7 \%)$ of neonates born at $\geqslant 34$ weeks gestation, and was statistically significant with $\mathrm{p}$ value $<0.001$. Trends in birth weight show a rise in occurrence of RDS with decreasing birth weight.

\begin{tabular}{|c|c|c|c|c|c|c|}
\hline & \multicolumn{4}{|l|}{ RDS } & \multirow{3}{*}{ Total } & \multirow{3}{*}{ P Value } \\
\hline & \multicolumn{2}{|l|}{ Yes } & \multicolumn{2}{|l|}{ No } & & \\
\hline & Frequency & Percentage & Frequency & Percentage & & \\
\hline \multicolumn{7}{|l|}{ Gender } \\
\hline Male & 19 & $13.9 \%$ & 118 & $86.1 \%$ & 137 & \multirow{2}{*}{0.186} \\
\hline Female & 11 & $8.2 \%$ & 123 & $91.8 \%$ & 134 & \\
\hline \multicolumn{7}{|c|}{ Gestational age (Weeks) } \\
\hline$<34$ & 15 & $32.6 \%$ & 31 & $67.4 \%$ & 46 & \multirow{2}{*}{$<0.001$} \\
\hline$\geq 34$ & 15 & $6.7 \%$ & 210 & $93.3 \%$ & 225 & \\
\hline \multicolumn{7}{|c|}{ Birth weight (kgs) } \\
\hline$<1.5$ & 24 & $20.2 \%$ & 95 & $79.8 \%$ & 119 & \multirow{2}{*}{0.111} \\
\hline $1.5-<2.5$ & 6 & $3.9 \%$ & 146 & $96.1 \%$ & 152 & \\
\hline
\end{tabular}

\section{TABLE 3: Association of RDS with Gender, Gestational Age and Birth Weight.}

RDS: Respiratory distress syndrome

According to Table 4, hypocalcemia was present in 21 (15.3\%) of the males and $16(11.9 \%)$ of the females. In regard to gestational age hypocalcemia was present in 13 (28.3\%) of neonates born at $<34$ weeks and in 24 $(10.7 \%)$ of neonates born at $\geqslant 34$ weeks gestation, and was statistically significant with $p$ value $<0.001$. In our study birth weight and hypocalcemia had significant association ( $\mathrm{p}$-value $<0.05$ ) and showed a decrease in occurrence of hypocalcemia with increase in birth weight.

\begin{tabular}{|c|c|c|c|c|c|c|}
\hline & \multicolumn{4}{|c|}{ Hypocalcemia } & \multirow{3}{*}{ Total } & \multirow{3}{*}{ P Value } \\
\hline & \multicolumn{2}{|l|}{ Yes } & \multicolumn{2}{|l|}{ No } & & \\
\hline & Frequency & Percentage & Frequency & Percentage & & \\
\hline \multicolumn{7}{|l|}{ Gender } \\
\hline Male & 21 & $15.3 \%$ & 116 & $84.7 \%$ & 137 & \multirow{2}{*}{0.263} \\
\hline Female & 16 & $11.9 \%$ & 118 & $88.1 \%$ & 134 & \\
\hline \multicolumn{7}{|c|}{ Gestational age (Weeks) } \\
\hline$<34$ & 13 & $28.3 \%$ & 33 & $71.7 \%$ & 46 & \multirow{2}{*}{$<0.001$} \\
\hline$\geq 34$ & 24 & $10.7 \%$ & 201 & $89.3 \%$ & 225 & \\
\hline \multicolumn{7}{|c|}{ Birth weight (kgs) } \\
\hline$<1.5$ & 26 & $22.0 \%$ & 92 & $78.0 \%$ & 118 & \multirow{2}{*}{0.009} \\
\hline $1.5-<2.5$ & 11 & $7.2 \%$ & 142 & $92.8 \%$ & 153 & \\
\hline
\end{tabular}

TABLE 4: Association of Hypocalcemia with Gender, Gestational Age and Birth Weight. 
regard to gestational age hypothermia was present in one $(2.2 \%)$ of neonates born at $<34$ weeks and in six $(2.7 \%)$ of neonates born at $\geqslant 34$ weeks gestation, which was not statistically significant. In our study birth weight and hypothermia had significant association (p-value $<0.05$ ) and showed a decrease in occurrence of hypothermia with increase in birth weight.

\begin{tabular}{|c|c|c|c|c|c|c|}
\hline & \multicolumn{4}{|l|}{ Hypothermia } & \multirow{3}{*}{ Total } & \multirow{3}{*}{ P Value } \\
\hline & \multicolumn{2}{|l|}{ Yes } & \multicolumn{2}{|l|}{ No } & & \\
\hline & Frequency & Percentage & Frequency & Percentage & & \\
\hline \multicolumn{7}{|l|}{ Gender } \\
\hline Male & 1 & $0.7 \%$ & 136 & $99.3 \%$ & 137 & \multirow{2}{*}{0.57} \\
\hline Female & 6 & $4.5 \%$ & 128 & $95.5 \%$ & 134 & \\
\hline \multicolumn{7}{|c|}{ Gestational age (Weeks) } \\
\hline$<34$ & 1 & $2.2 \%$ & 45 & $97.8 \%$ & 46 & \multirow{2}{*}{0.41} \\
\hline$\geq 34$ & 6 & $2.7 \%$ & 219 & $97.3 \%$ & 225 & \\
\hline \multicolumn{7}{|c|}{ Birth weight (kgs) } \\
\hline$<1.5$ & 6 & $5.1 \%$ & 112 & $94.9 \%$ & 118 & \multirow{2}{*}{0.029} \\
\hline $1.5-<2.5$ & 1 & $0.7 \%$ & 152 & $99.3 \%$ & 153 & \\
\hline
\end{tabular}

TABLE 5: Association of Hypothermia with Gender, Gestational Age and Birth Weight.

\section{Discussion}

Neonatal morbidity and mortality are a critical public health issue across many developing countries. Among multitude of factors, prematurity and low birth weight are major predictors of morbidity and mortality. Despite attempts at devising strategies for improving health status and preventing diseases, little has been achieved in terms of decrease in neonatal morbidity and mortality across various parts of the world. The causes attributing to the consistently increased neonatal mortality rate (NMR) are antenatal, perinatal and postnatal factors. Present study reflects that there was a gradual decline in morbidity with increasing gestational age and birth weight. Therefore, measures such as provision of adequate antenatal and postnatal care, as well as prevention of complications in pregnancy to achieve adequate weight at birth, as well as to prevent preterm delivery are factors that are significantly important in reducing neonatal morbidity.

The frequency of morbidity and mortality among neonates reflects the quality of antenatal, intrapartum and postnatal care, and varies across different institutes and even countries. In developing countries with limited facilities, the survival of high-risk neonates tends to be low, in particular due to inability to address early morbidities in neonatal period. Early morbidities observed in our study were also found in a study conducted by Basu et al., which showed that common morbidities of low birth weight included RDS, apnea, sepsis, hypothermia, hypoglycemia, shock and intraventricular hemorrhage (IVH) [14].

Frequency of hypoglycemia has a wide variability across literature. A study conducted on low birth weight infants found that hypoglycemia occurred in $24 \%$ of infants, however, in our study we observed that $17.3 \%$ of low birth weight neonates had episodes of hypoglycemia [15]. According to a study conducted in India, $8.4 \%$ of LBW neonates developed hypothermia, while in our study we found that hypothermia occurred in $2.5 \%$ of low birth weight neonates, with no significant associations with gender and gestational age, however, birth weight and hypothermia had significant association (p-value $<0.05$ ) [12]. In respiratory distress syndrome occurring in this population no significant association was found with birth weight, and literature seems to be very divided on it. However, different studies on RDS have observed that it has no significant association with gender, a finding consistent with our study [16]. There was a positive correlation between gestational age and RDS, which too was consistent with our study [17]. A study on low birth weight neonates found the frequency of hypocalcemia to be $24.4 \%$, our study however found a frequency of $13.6 \%$ [13]. There was also significant association of hypoglycemia with gestational age and birth weight.

\section{Conclusions}

Our study highlighted major early morbidities of LBW neonates, and their association with birth weight, gestational age and gender. Significant association of birth weight was found with hypothermia and hypocalcemia, whereas hypocalcemia and RDS were significantly associated with gestational age. However, 
none of the early morbidities had significant association with gender. In order to minimize early morbidities in low birth weight neonates, adequate consideration should be given to this high-risk population by the health care providers. The data acquired through this study will subsequently be used not only in creating awareness among medical practitioners dealing with neonates, but also in developing protocols for appropriate management and prevention of such morbidities.

\section{Additional Information}

\section{Disclosures}

Human subjects: Consent was obtained by all participants in this study. The Aga Khan University Hospital Ethics Review Committee issued approval 3717-Ped-ERC-15. Consent was obtained from all participants in this study. The Aga Khan University Hospital Ethics Review Committee issued approval; 3717-Ped-ERC-15. Animal subjects: All authors have confirmed that this study did not involve animal subjects or tissue. Conflicts of interest: In compliance with the ICMJE uniform disclosure form, all authors declare the following: Payment/services info: All authors have declared that no financial support was received from any organization for the submitted work. Financial relationships: All authors have declared that they have no financial relationships at present or within the previous three years with any organizations that might have an interest in the submitted work. Other relationships: All authors have declared that there are no other relationships or activities that could appear to have influenced the submitted work.

\section{References}

1. Imdad A, Bhutta ZA: Nutritional management of the low birth weight/preterm infant in community settings: a perspective from the developing world. J Pediatrics. 2013, 162:107-114. 10.1016/j.jpeds.2012.11.060

2. Neonatal and perinatal mortality 2000: country, regional and global estimates . (2006). Accessed: November 3, 2019: https://www.who.int/maternal_child_adolescent/documents/9241563206/en/.

3. Gouyon JB, Vintejoux A, Sagot P, Burguet A, Quantin C, Ferdynus C; Burgundy Perinatal Network: Neonatal outcome associated with singleton birth at 34-41 weeks of gestation. Int J Epidemiol. 2010, 39:769-776. 10.1093/ije/dyq037

4. Yasmin S, Osrin D, Paul E, Costello A: Neonatal mortality of low-birth-weight infants in Bangladesh . Bull World Health Organ. 2001, 79:608-614.

5. Brown HK, Speechley KN, Macnab J, Natale R, Campbell MK: Neonatal morbidity associated with late preterm and early term birth: the roles of gestational age and biological determinants of preterm birth. Int J Epidemiol. 2014, 43:802-814. 10.1093/ije/dyt251

6. Stoltzfus RJ, Rasmussen KM: The dangers of being born too small or too soon. Lancet. 2013, 382:380-381. 10.1016/S0140-6736(13)61567-6

7. Flamant C, Gascoin G: Short-term outcome and small for gestational age newborn management. (Article in French). J Gynecol Obstet Biol Reprod (Paris). 2013, 42:985-995. 10.1016/j.jgyn.2013.09.020

8. Kramer MS, Olivier M, McLean FH, Willis DM, Usher RH: Impact of intrauterine growth retardation and body proportionality on fetal and neonatal outcome. Pediatrics. 1990, 86:707-713.

9. Raju TN: The problem of late-preterm (near-term) births: a workshop summary. Pediatr Res. 2006, 60:775776. 10.1203/01.pdr.0000246074.73342.1e

10. Saigal S, Doyle LW: An overview of mortality and sequelae of preterm birth from infancy to adulthood . Lancet. 2008, 371:261-269. 10.1016/S0140-6736(08)60136-1

11. Harris DL, Hons M, Weston PJ, Harding JE: Incidence of neonatal hypoglycemia in babies identified as at risk. J Pediatr. 2012, 161:787-791. 10.1016/j.jpeds.2012.05.022

12. Kaushik S, Grover N, Parmer VR, Grover PS, Kaushik R: Neonatal morbidity in a hospital at Shimla . Indian J Pediatr. 1999, 66:15-19. 10.1007/bf02752343

13. Honarpisheh A: Frequency of hypocalcemia in low birth weight infants at hospitals in Kashan in 1997 . Med J Islam Repub Iran. 2003, 17:47-50.

14. Basu S, Rathore P, Bhatia BD: Predictors of mortality in very low birth weight neonates in India . Singapore Med J. 2008, 49:556-560.

15. Saini A, Gaur BK, Singh P: Hypoglycemia in low birth weight neonates: frequency, pattern, and likely determinants. Int J Contemp Pediatrics. 2018, 5:526-532. 10.18203/2349-3291.ijcp20180548

16. Canbak Y, Silfeler I, Dorum BA, Kurnaz H, Dorum S: The ratio of mortality and morbidity in very low birth weight infants in a public hospital. Turk Arch Pediatr. 2011, 46:144-150. 10.4274/tpa.46.62

17. Chang H, Sung Y, Wang S, et al.: Short- and long-term outcomes in very low birth weight infants with admission hypothermia. PLoS ONE. 2015, 10:e0131976. 10.1371/journal.pone.0131976 